\title{
DECISION SUPPORT SYSTEM PERUSAHAAN MANUFACTURING DALAM MENENTUKAN PEMASOK MENGGUNAKAN METODE ANALYTICAL HIERARCHY PROCESS
}

\author{
Henny Hartono ${ }^{1}$, Johanes Fernandes Andry ${ }^{2}$, Berliana Glorya Liebe Imbing ${ }^{3}$, \\ Catherine Gunawan ${ }^{4}$ \\ ${ }^{1,2,3,4}$ Program Studi Sistem Informasi Universitas Bunda Mulia Jakarta, Indonesia \\ E-mail: Jf.andry@smartlearning.co.id
}

\begin{abstract}
Suppliers are one of the important things in purchasing activities of various needs for the company. Supplier selection is a multi-criteria problem that includes quantitative and qualitative factors. One method that can be used for supplier selection is the Analytical Hierarchy Process (AHP) method. This research was conducted at Manufacturing companies in relations with suppliers who will develop a partnership relationship between companies and suppliers. The purpose of this research is that the right supplier can help the company in increasing competitiveness that can increase company revenue. To help companies choose the right supplier, a decision support system is needed. The variables used in this paper are price, quality, service, delivery accuracy and quantity. The most determining criterion in selecting suppliers is the accuracy of delivery criteria, making these criteria a major factor in supplier selection. The results of this study are consistency in delivering goods on time and guaranteeing safety in guaranteeing the quality of a product.
\end{abstract}

Keywords: Suppliers, Companies, AHP, SPK.

\begin{abstract}
ABSTRAK
Pemasok merupakan salah satu hal yang penting dalam aktivitas pembelian berbagai kebutuhan bagi perusahaan. Pemilihan pemasok merupakan masalah multi kriteria yang meliputi faktor-faktor kuantitatif dan kualitatif. Salah satu metode yang bisa digunakan untuk pemilihan pemasok adalah metode Analytical Hierarchy Process (AHP). Penelitian ini dilakukan pada sebuah perusahaan Manufacturing dalam hubungan dengan pemasok yang akan mengembangkan hubungan kemitraan antara perusahaan dengan pemasok. Tujuan dari penelitian ini ialah Pemasok yang tepat diharapkan dapat membantu menunjang perusahaan dalam meningkatkan daya saing yang kedepannya dapat meningkatkan pendapatan perusahaan. Untuk membantu perusahaan dalam memilih pemasok yang tepat maka dibutuhkan sebuah sistem pendukung keputusan. Variabel yang digunakan pada paper ini adalah harga, kualitas, layanan, ketepatan pengiriman dan ketepaan jumlah. Kriteria yang paling berpengaruh dalam pemilihan supplier adalah kriteria ketepatan pengiriman, menjadikan kriteria tersebut faktor utama dalam pemilihan supplier. Hasil dari penelitian ini adalah konsistensi dalam mengirim barang tepat waktu dan menjamin keamanannya dalam menjaga kualitas suatu produk.
\end{abstract}

Kata Kunci: Pemasok, Perusahaan, AHP, SPK.

\section{PENDAHULUAN}

Pengambilan keputusan, pada dasarnya merupakan bentuk pemilihan dari berbagai alternatif tindakan yang mungkin bisa dipilih (Nurmalasari \& Pratama, 2018).

Sistem ini digunakan untuk membantu pengambilan keputusan dalam situasi semi terstruktur dan situasi yang tidak terstruktur, dimana tidak ada seorangpun yang tahu secara pasti bagaimana keputusan seharusnya dibuat (Ahmad Fauzi, 2016).
Keputusan yang akan diambil bersifat kompleks dengan risiko yang besar seperti perumusan kebijakan, pengambil keputusan sering memerlukan alat bantu dalam bentuk yang bersifat ilmiah, logis, dan terstruktur. Pemilihan pemasok merupakan kegiatan strategis, terutama apabila pemasok tersebut akan memasok item yan kritis dan/atau akan digunakan dalam jangka panjang (Dewayana \& Budi, 2009).

Dalam mengambil keputusan untuk memilih pemasok, pengambil keputusan (decision maker) membutuhkan alat analisis yang memungkinkan mereka untuk memecahkan 
masalah yang bersifat kompleks sehingga keputusan yang diambil lebih berkualitas. Pemilihan pemasok harus dilakukan secara hatihati karena pemilihan pemasok yang salah akan menyebabkan terganggunya proses produksi dan operasional perusahaan.

Pemilihan pemasok merupakan masalah multi kriteria yang meliputi faktor-faktor kuantitatif dan kualitatif. Beberapa kriteria yang berpengaruh pada pemilihan pemasok ini ada yang bersifat kuantitatif dan kualitatif. Oleh karena itu diperlukan metode yang bisa menyertakan keduanya dalam pengukuran. Salah satu metode yang bisa digunakan untuk pemilihan pemasok adalah metode AHP (Analytical Hierarchy Process). Metode ini menyertakan ukuran-ukuran kualitatif dan kuantitatif. AHP adalah metode pengambilan keputusan yang dikembangkan untuk pemberian prioritas beberapa alternatif ketika beberapa kriteria harus dipertimbangkan, serta mengijinkan pengambil keputusan untuk menyusun masalah yang kompleks ke dalam suatu bentuk hirarki atau serangkaian level yang terintegrasi (Reny Rahmayanti, 2010).

Analytical Hierarchy Process merupakan suatu metode pendukung keputusan yang dikembangkan oleh Thomas L. Saaty pada tahun 1993. Model pendukung keputusan ini akan menguraikan masalah multi faktor atau multi kriteria yang kompleks menjadi suatu hierarki. Hierarki didefinisikan sebagai suatu representasi dari sebuah permasalahan yang kompleks dalam suatu struktur multilevel dimana level pertama adalah tujuan, yang diikuti level faktor, kriteria, sub kriteria, dan seterusnya hingga level terakhir dari alternatif (Munthafa \& Mubarok, 2017).

Pada hakekatnya AHP merupakan suatu model pengambil keputusan yang komprehensif dengan memperhitungkan hal-hal yang bersifat kualitatif dan kuantitatif (Sasongko et al., 2017).

Kadang kala, kriteria-kriteria ini saling bertentangan satu sama lain. Sebagai contoh, suatu pemasok lebih memilih menawarkan harga lebih rendah dengan kualitas di bawah rata-rata, sementara pemasok lain menawarkan barang dengan kualitas baik dengan pengiriman yang tidak pasti. Bagaimanapun sulit untuk menemukan pemasok yang bisa memenuhi semua kriteria atau yang baik dalam semua kriteria, tetapi paling tidak bisa menemukan pemasok yang optimal bagi perusahaan. Proses pemilihan pemasok ini bermula dari kebutuhan akan pemasok, menentukan dan merumuskan kriteria keputusan, pre-kualifikasi (penyaringan awal dan menyiapkan sebuah shortlist pemasok potensial dari suatu daftar pemasok/pemasok), pemilihan pemasok akhir, dan monitoring pemasok terpilih, yaitu evaluasi dan penilaian berlanjut. Pertumbuhan globalisasi dan perkembangan teknologi informasi mengakibatkan persaingan bisnis antar perusahaan menjadi semakin ketat.
Perusahaan-perusahaan berupaya untuk meningkatkan performasinya dalam rangka menghasilkan suatu output yang optimal, yang mampu memenuhi keinginan konsumen. Salah satu faktor yang memengaruhi performasi perusahaan adalah keberadaan pemasok yang berperan sebagai pemasok bahan baku. Keberadaan pemasok ini sangat menentukan kelancaran proses produksi dan produk yang akan dihasilkan. Maka, perlunya pemilihan pemasok adalah proses menemukan pemasok yang cocok yang dapat menyediakan pembeli dengan produk atau jasa yang berkualitas yang tepat pada harga yang tepat, dalam jumlah yang tepat dan pada waktu yang tepat (Basuki, 2010).

\section{METODE PENELITIAN}

\section{Tahapan Penelitian}

Metode penelitian adalah proses dalam melaksanakan penelitian yang mengarah ke proses dan hasil penelitian sedapat mungkin menjadi valid, obyektif, efisien, dan efektif.

Berdasarkan Gambar 1 Tahapan Penelitian, diperlihatkan bahwa tahapan Awal, melakukan persiapan baik dalam pengkajian bahan pustaka dan focus perhatian penelitian untuk mendapat referensi penelitian yang tepat sebagai ketepatan rancangan penelitian serta pemahaman dalam penyusunan teori.

Penetapan Masalah, Setelah mendapat referensi yang cocok dalam melakukan penelitian, maka dapat ditarik suatu permasalahan dari semua bahan rujukan yang telah didapat dalam pada sistem pemilihan pemasok.

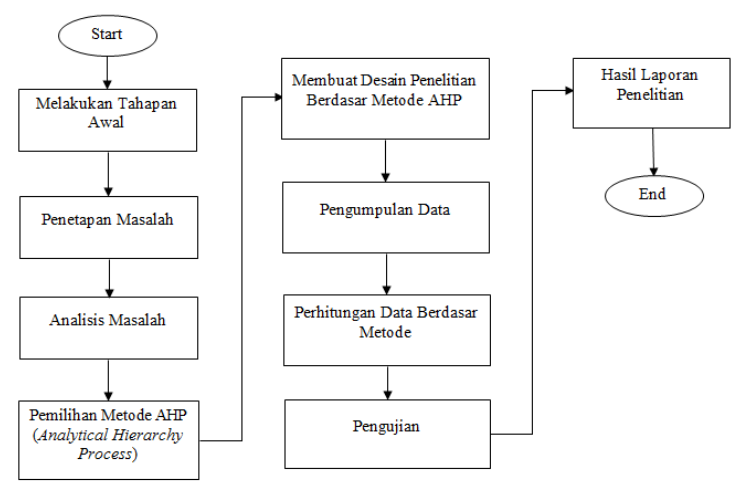

Sumber : (Henny Hartono, Johanes Fernandes Andry \& Gunawan, 2019)

Gambar 1. Tahapan Penelitian

Analisis, Setelah mendapat permasalahan yang cocok dalam melakukan penelitian, maka langka selanjutnya adalah menganalisis masalah tersebut. Analisis dilakukan untuk memahami sistem yang dibuat, mendeskripsikan sistem, menentukan input dan output dari sistem yang dibuat serta kebutuhan lain yang digunakan oleh sistem pemilihan pemasok. 
Penetapan Metode AHP, Dalam mempermudah penelitian dalam menyelesaikan masalah, perlunya suatu metode dalam membantu menyelesaikan permasalahan tersebut. Menetapkan metode AHP yang tepat dengan penelitian yang dilakukan

Desain, Perancangan dilakukan setelah mendapatkan hasil dari tahap analisis. Perancangan pemilihan pemasok terdiri dari deskripsi sistem, perancangan analisis proses dengan menggunakan diagram aliran data, perancangan subsistem model atau metode yang digunakan yaitu AHP, dan perancangan subsistem dialog yang merupakan interface antara sistem dengan pemakai.

Pengumpulan Data, Pengumpulan Data menggunakan metode studi pustaka merupakan metode yang digunakan untuk mencari teori-teori, konsep-konsep, generalisasi-generalisasi yang dapat dijadikan landasan teoritis bagi penelitian yang dilakukan. Landasan teoritis digunakan agar penelitian mempunyai dasar yang kokoh.

Perhitungan Data, Pada perhitungan data ini, menggunakan tahapan perbandingan berpasangan. Tahapan perbandingan berpasangan ini akan digunakan pada saat mencari/menghitung bobot kriteria dan bobot alternatif untuk setiap kriteria penilaian. Perbandingan berpasangan dilakukan berdasarkan preferensi subyektif dari pengambil keputusan.

Tes (Pengujian/Pengecekan), Tahap pengujian dilakukan setelah bobot kriteria didapatkan, yaitu untuk mengetahui apakah keputusan yang dibuat telah sesuai dengan analisis kebutuhan yang dilakukan di tahap awal serta hasil pengujian tersebut akan dianalisis untuk mengetahui kelebihan dan kekurangan.

\section{Langkah Metode AHP}

Pada Gambar 2 diperlihatkan Langkahlangkah Metode AHP, yaitu:

1. Penyusunan Struktur Hirarki

Hirarki masalah disusun untuk membantu proses pengambilan keputusan dengan memperhatikan seluruh elemen keputusan yang terlibat dalam sistem.

2. Penentuan Prioritas

Kegiatan perbandingan antar sepasang objek, penggunaan metode AHP memberikan standar penilaian perbandingan antar dua objek

3. Bobot Kriteria

Menghitung bobot/prioritas kepentingan dari masing-masing variable

4. Pemilihan Pemasok Optimal

Melakukan sintesis untuk mendapatkan bobot alternatif secara keseluruhan dari kriteria yang ada, bobot masing-masing alternatif secara keseluruhan dapat dihitung dengan menjumlahkan semua bobot keseluruhan pada masing-masing pemasok

\section{Indeks Konsistensi}

Pengukuran konsistensi dari suatu matriks itu sendiri didasarkan atas eigenvalue maksimum. Dengan eigenvalue maksimum, inkonsistensi yang biasa dihasilkan matriks perbandingan dapat diminimumkan.

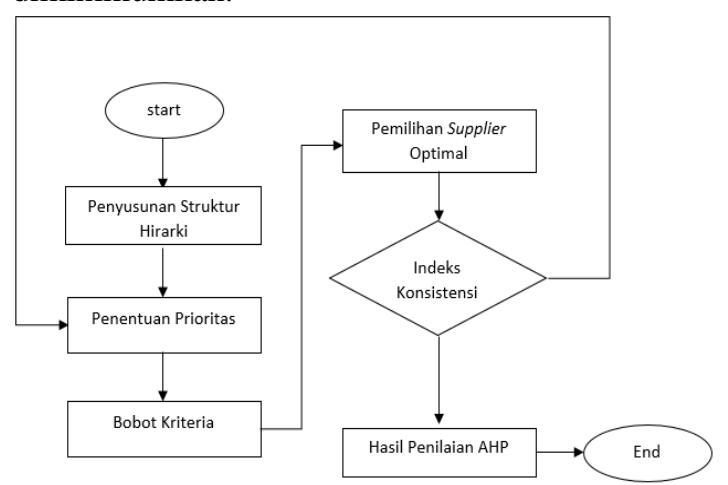

Sumber : (Henny Hartono, Johanes Fernandes Andry \& Gunawan, 2019)

Gambar 2. Langkah-langkah Metode AHP

\section{Model, Variabel dan Indikator Penelitian}

Pada paper ini, mengacuh pada tahapan yang mengacuh pada model sekuensial linier. Tahapan yang harus digunakan guna untuk mempermudah penganalisa system atau aplikasi yang digunakan untuk membantu keputusan dalam memilih pemasok yang sesuai dengan kebutuhan konsumen dan perusahaan.

\section{Penyusunan Variabel dan Indikator Penelitian}

Dari hasil analisa pendahuluan didapatkan variabel-variabel (kriteria) yang digunakan dalam pemilihan pemasok perusahaan, yaitu sebagai berikut:

\section{Harga (Price)}

Harga adalah nilai benda/barang diukur dengan satuan uang (rupiah), diukur dengan Skala Penilaian Perbandingan Berpasangan. Harga di sini meliputi 2 subkriteria:

a.Kepantasan harga dengan kualitas barang yang dihasilkan (H1).

b.Kemampuan untuk memberikan potongan harga (diskon) pada pemesanan dalam jumlah tertentu (H2).

\section{Kualitas (Quality)}

Kualitas adalah totalitas bentuk dan karakteristik barang atau jasa yang menunjukkan kemampuannya untuk memuaskan kebutuhan. Kualitas produk diukur dengan kualitas, ketahanan, build quality, ada tidaknya kecacatan, serta kelayakkan pemakaian, diukur dengan Skala Penilaian Perbandingan Berpasangan. Kualitas di sini meliputi 3 subkriteria:

a.Kesesuaian barang dengan spesifikasi yang sudah ditetapkan (Q1).

b.Penyediaan barang tanpa cacat (Q2).

c.Kemampuan memberikan kualitas yang konsisten(Q3). 


\section{Layanan (Service)}

Layanan adalah pelayanan, bantuan dan kemudahan yang diberikan pemasok kepada konsumen (pihak perusahaan), diukur dengan Skala Penilaian Perbandingan Berpasangan.

Layanan di sini meliputi 4 subkriteria:

a.Kemudahan untuk dihubungi (S1).

b.Kemampuan memberikan informasi secara jelas dan mudah dimengerti (S2).

c.Kecepatan dalam hal menanggapi permintaan pelanggan (S3).

d.Cepat tanggap dalam menyelesaikan keluhan pelanggan (S4).

4. Ketepatan Pengiriman (Delivery)

Ketepatan pengiriman yaitu kemampuan pemasok dalam menangani permintaan perusahaan sehingga dapat mengirimkan barang sesuai dengan waktu yang sudah ditentukan diukur dengan Skala Penilaian Perbandingan Berpasangan. Ketepatan pengiriman di sini meliputi 2 subkriteria:

a.Kemampuan untuk mengirimkan barang sesuai dengan tanggal yang telah disepakati (D1).

b.Kemampuan dalam hal penanganan sistem transportasi (D2).

5. Ketepatan Jumlah (Quantity)

Ketepatan jumlah yaitu ketepatan dan kesesuaian jumlah dalam pengiriman, diukur dengan Skala Penilaian Perbandingan Berpasangan.

\section{HASIL DAN PEMBAHASAN}

\section{Penyusunan Hirarki}

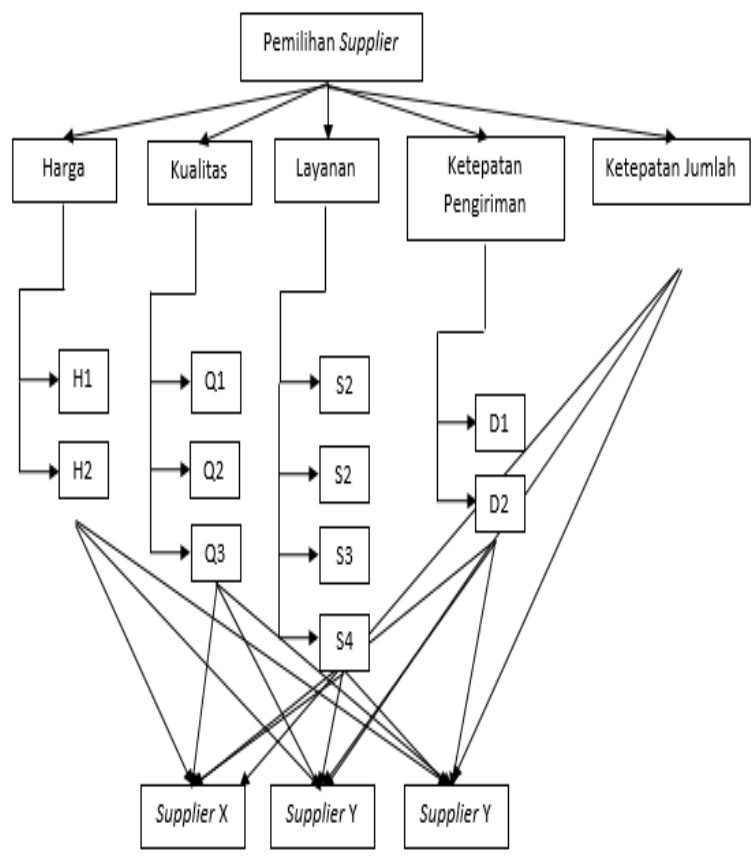

Sumber : (Henny Hartono, Johanes Fernandes Andry \& Gunawan, 2019)

Gambar 3. Struktur Hirarki Masalah Pemilihan Supplier
Dalam AHP, kriteria biasanya disusun ke dalam bentuk hirarki. Kriteria dan subkriteria sering dipakai oleh suatu perusahaan manufactur dalam memilih supplier. Masalah dalam pemilihan supplier dalam hal ini dibagi ke dalam 3 level. Level 0 merupakan tujuan dalam memilih supplier terbaik, level 1 merupakan pemilihan supplier berdasarkan kriteria, level 2 merupakan subkriteria hasil penjabaran dari level 1, dan level 3 merupakan alternatif, supplier mana yang seharusnya dipilih.

\section{Matriks Perbandingan}

Tabel 1. Tabel Standar Perbandingan

\begin{tabular}{|l|l|}
\hline \multicolumn{1}{|c|}{ Sistaks Pembanding } & Nilai \\
\hline Sangat Diutamakan & 9 \\
\hline $\begin{array}{l}\text { Lebih Diutamakan Menuju Sangat } \\
\text { Diutamakan }\end{array}$ & 8 \\
\hline Lebih Diutamakan & 7 \\
\hline Diutamakan Menuju Diutamakan & 6 \\
\hline Diutamakan & 5 \\
\hline $\begin{array}{l}\text { Cukup Diutamakan Menuju } \\
\text { Diutamakan }\end{array}$ & 4 \\
\hline Cukup Diutamakan & 3 \\
\hline Setara Menujuh Cukup Diutamakan & 2 \\
\hline Setara Gunawan, 2019) & 1 \\
\hline Sumber : (Henny Hartono, Johanes Fernandes Andry \&
\end{tabular}

Data nilai pada Tabel 1. Tabel Standar Perbandingan merupakan bentuk kualitatif dari sintaks perbandingan yang dimulai dari nilai tertinggi (9: Sangat Diutamakan) sampai dengan ke nilai yang paling rendah (1: Setara).

Penggunaan metode AHP harus konsisten dalam membandingkan antar pasangan objek agar solusi terbaik yang dihasilkan. Jawaban yang tidak konsisten akan berdampak besar pada solusi yang tidak optimal. Urutan langkah dalam metode AHP adalah:

a. Lakukan pairwise comparison, yaitu menentukan perbandingan antara satu kriteria dengan kriteria yang lain berdasarkan tingkat kepentingan kriteria mana yang lebih penting.

b. Mengulangi langkah-1 pada setiap kriteria.

c. Mengurutkan setiap kriteria berdasarkan keutamaannya.

Hasil yang didapatkan dari tabel 2, kemudian dimodelkan kedalam perbandingan pasangan (gambar 1), dan matriks tersebut menjalani proses normalisasi menggunakan metode Eigenvector. Proses normalisasi matriks dimaksudkan untuk menemukan urutan prioritas. 
Tabel 2. Tabel Pairwaise Comparison untuk Perbandingan antar Sepasang Kriteria

\begin{tabular}{|l|l|l|}
\hline Kriteria-1 & \multicolumn{1}{|c|}{ Perbandingan } & Kriteria-2 \\
\hline Kualitas & $\begin{array}{l}\text { Setara Menujuh Cukup } \\
\text { Diutamakan (2) }\end{array}$ & Harga \\
\hline Harga & Cukup Diutamakan (3) & Layanan \\
\hline $\begin{array}{l}\text { Ketepatan } \\
\text { Pengiriman }\end{array}$ & Diutamakan (5) & Harga \\
\hline Kualitas & Diutamakan (5) & Layanan \\
\hline $\begin{array}{l}\text { Ketepatan } \\
\text { Pengiriman }\end{array}$ & $\begin{array}{l}\text { Cukup Diutamakan } \\
\text { Menuju Diutamakan (4) }\end{array}$ & Kualitas \\
\hline $\begin{array}{l}\text { Ketepatan } \\
\text { Pengiriman }\end{array}$ & $\begin{array}{l}\text { Cukup Diutamakan } \\
\text { Menuju Diutamakan (5) }\end{array}$ & Layanan \\
\hline
\end{tabular}

Sumber : (Henny Hartono, Johanes Fernandes Andry \& Gunawan, 2019)

\begin{tabular}{|c|c|c|c|c|}
\hline kriteria & harga & kualitas & layanan & ketepatan pengiriman \\
\hline harga & $1 / 1$ & $1 / 2$ & $3 / 1$ & $1 / 5$ \\
\hline kualitas & $2 / 1$ & $1 / 1$ & $5 / 1$ & $1 / 4$ \\
\hline layanan & $1 / 3$ & $1 / 5$ & $1 / 1$ & $1 / 5$ \\
\hline $\begin{array}{l}\text { ketepatan } \\
\text { pengiriman }\end{array}$ & $5 / 1$ & $4 / 1$ & $5 / 1$ & $1 / 1$ \\
\hline
\end{tabular}

Sumber : (Henny Hartono, Johanes Fernandes Andry \& Gunawan, 2019)

Gambar 4. Matriks Perbandingan Pasangan yaitu:

Langkah penerapan metode Eigenvector

a) Kuadratkan matriks pairwise dengan proses perkalian matriks.

b) Lakukan penjumlahkan terhadap setiap baris.

c) Lakukan normalisasi matriks.

d) Melakukan integrase langkah-1 sampai dengan langkah-3 sehingga diperoleh selisih nilai eigen antar dua iterasi relatif kecil $(<0,000010)$.

Dalam menggambarkan kontribusi relatif, dibuat matrik perbandingan berpasangan terhadap pengaruh setiap elemen terhadap masing-masing tujuan kriteria. Bertujuan dalam memperoleh bobot penilaian dari setiap variable, dibuatnya skala perbandingan berpasangan seperti pada tabel 3 .

Tabel 3 Matriks Perbandingan Berpasangan Tujuan Antar Kriteria Dalam Pemilihan Supplier

\begin{tabular}{|c|c|c|c|c|c|}
\hline $\begin{array}{c}\text { Kriteri } \\
\text { a }\end{array}$ & $\begin{array}{c}\text { Har } \\
\text { ga }\end{array}$ & $\begin{array}{c}\text { Kuali } \\
\text { tas }\end{array}$ & $\begin{array}{c}\text { Laya } \\
\text { nan }\end{array}$ & $\begin{array}{c}\text { Ketepat } \\
\text { an } \\
\text { Pengiri } \\
\text { man }\end{array}$ & $\begin{array}{c}\text { Ketepa } \\
\text { tan } \\
\text { Jumla } \\
\text { h }\end{array}$ \\
\hline Harga & 1 & & & & \\
\hline $\begin{array}{c}\text { Kualita } \\
\text { s }\end{array}$ & & 1 & & & \\
\hline $\begin{array}{c}\text { Layana } \\
\text { n }\end{array}$ & & & 1 & & \\
\hline $\begin{array}{c}\text { Ketepat } \\
\text { an } \\
\begin{array}{c}\text { Pengiri } \\
\text { man }\end{array}\end{array}$ & & & 1 & \\
\hline $\begin{array}{c}\text { Ketepat } \\
\text { an } \\
\text { Jumlah }\end{array}$ & & & & & 1 \\
\hline
\end{tabular}

Sumber : (Henny Hartono, Johanes Fernandes Andry \& Gunawan, 2019)
Agar diperoleh bobot penilaian dari masing-masing variabel maka dibuat tabel skala penilaian perbandingan berpasangan. Adapun bentuk tabelnya sebagai berikut:

Tabel 4. Matriks Perbandingan Berpasangan Tujuan Antar Subkriteria pada Kriteria Harga

\begin{tabular}{|c|c|c|}
\hline Subkriteria & $\begin{array}{c}\text { Kepantasan } \\
\text { Harga dengan } \\
\text { Kualitas (H1) }\end{array}$ & $\begin{array}{c}\text { Kemampuan } \\
\text { Memberikan } \\
\text { Diskon (H2) }\end{array}$ \\
\hline $\begin{array}{c}\text { Kepantasan Harga } \\
\text { dengan Kualitas } \\
\text { (H1) }\end{array}$ & 1 & \\
\hline $\begin{array}{c}\text { Kemampuan } \\
\text { Memberikan } \\
\text { Diskon (H2) }\end{array}$ & & 1 \\
\hline
\end{tabular}

Sumber : (Henny Hartono, Johanes Fernandes Andry \& Gunawan, 2019)

Tabel 5 Matriks Perbandingan Berpasangan Tujuan Antar Subkriteria pada Kriteria Kualitas

\begin{tabular}{|c|c|c|c|}
\hline Subkriteria & $\begin{array}{c}\text { Kesesuaian barang } \\
\text { dengan spesifikasi } \\
\text { yang ditetapkan (Q1) }\end{array}$ & $\begin{array}{c}\text { Penyediaan barang } \\
\text { tanpa cacat (Q2) }\end{array}$ & $\begin{array}{c}\text { Kemampuan } \\
\text { memberikan kualitas } \\
\text { yang konsisten (Q3) }\end{array}$ \\
\hline $\begin{array}{c}\text { Kesesuaian barang } \\
\text { dengan spesifikasi } \\
\text { yang ditetapkan } \\
\text { (Q1) }\end{array}$ & 1 & & \\
\hline $\begin{array}{c}\text { Penyediaan barang } \\
\text { tanpa cacat (Q2) }\end{array}$ & 1 & 1 & \\
\hline $\begin{array}{c}\text { Kemampuan } \\
\text { memberikan kualitas } \\
\text { yang konsisten (Q3) }\end{array}$ & & & 1 \\
\hline
\end{tabular}

Sumber : (Henny Hartono, Johanes Fernandes Andry \& Gunawan, 2019)

Tabel 6. Matriks Perbandingan Berpasangan Tujuan Antar Subkriteria pada Kriteria Layanan

\begin{tabular}{|c|c|c|c|c|}
\hline Subkriteria & $\begin{array}{c}\text { Kemudahan } \\
\text { untuk } \\
\text { dihubungi } \\
\text { (S1) }\end{array}$ & $\begin{array}{c}\text { Kemampuan } \\
\text { memberikan } \\
\text { informasi secara } \\
\text { jelas (S2) }\end{array}$ & $\begin{array}{c}\text { Kecepatan } \\
\text { menanggapi } \\
\text { permintaan } \\
\text { pelanggan (S3) }\end{array}$ & $\begin{array}{c}\text { Cepat tanggap } \\
\text { menyelesaikan } \\
\text { keluhan } \\
\text { pelanggan (S4) }\end{array}$ \\
\hline $\begin{array}{c}\text { Kemudahan } \\
\text { untuk } \\
\text { dihubungi } \\
\text { (S1) }\end{array}$ & 1 & & & \\
\hline $\begin{array}{c}\text { Kemampuan } \\
\text { memberikan } \\
\text { informasi } \\
\text { secara jelas } \\
\text { (S2) }\end{array}$ & & 1 & & \\
\hline $\begin{array}{c}\text { Kecepatan } \\
\text { menanggapi } \\
\text { permintaan } \\
\text { pelanggan } \\
\text { (S3) }\end{array}$ & & & & \\
\hline $\begin{array}{c}\text { Cepat tanggap } \\
\text { menyelesaikan } \\
\text { keluhan } \\
\text { pelanggan } \\
\text { (S4) }\end{array}$ & & & 1 & \\
\hline
\end{tabular}

Sumber : (Henny Hartono, Johanes Fernandes Andry \& Gunawan, 2019)

Agar diperoleh bobot penilaian dari masing-masing variabel maka dibuat tabel 7. Skala penilaian perbandingan berpasangan yang berlaku untuk semua kriteria dan subkriteria yang telah ditetapkan, antara lain pada kriteria harga terdapat subkriteria kepantasan harga dengan kualitas barang dan subkriteria kemampuan memberikan diskon.

Pada kriteria kualitas terdapat subkriteria kesesuaian barang dengan spesifikasi yang ditetapkan, subkriteria penyediaan barang tanpa cacat, dan subkriteria kemampuan memberikan kualitas yang konsisten. 
Pada kriteria layanan terdapat subkriteria kemudahan dihubungi, subkriteria memberikan informasi secara jelas, subkriteria kecepatan menanggapi permintaan pelanggan, dan subkriteria cepat tanggap menyelesaikan keluhan pelanggan.

Pada kriteria ketepatan pengiriman terdapat subkriteria kemampuan mengirimkan barang sesuai tanggal yang disepakati, dan subkriteria kemampuan dalam menangani sistem transportasi. Terhadap kriteria ketepatan jumlah berupa ketepatan jumlah barang yang sudah dipesan sepakati.

Tabel 7. Matriks Perbandingan Berpasangan Tujuan Antar Alternatif

\begin{tabular}{|c|c|c|c|c|}
\hline $\begin{array}{c}\text { Alterna } \\
\text { tif }\end{array}$ & $\begin{array}{c}\text { Suppli } \\
\text { er W }\end{array}$ & $\begin{array}{c}\text { Suppli } \\
\text { er X }\end{array}$ & $\begin{array}{c}\text { Suppli } \\
\text { er Y }\end{array}$ & $\begin{array}{c}\text { Suppli } \\
\text { er Z }\end{array}$ \\
\hline $\begin{array}{c}\text { Supplie } \\
\text { r W }\end{array}$ & 1 & & & \\
\hline $\begin{array}{c}\text { Supplie } \\
\text { r X }\end{array}$ & & 1 & & \\
\hline $\begin{array}{c}\text { Supplie } \\
\text { r Y }\end{array}$ & & & 1 & \\
\hline $\begin{array}{c}\text { Supplie } \\
\text { r Z }\end{array}$ & & & & 1 \\
\hline
\end{tabular}

Sumber : (Henny Hartono, Johanes Fernandes Andry \& Gunawan, 2019)

\section{Perhitungan Bobot Kriteria}

Menghitung bobot/prioritas kepentingan dari masing-masing variabel pada level 1 (kriteria) yaitu Harga, Kualitas, Layanan, Ketepatan Pengiriman, dan Ketepatan Jumlah.

Data untuk pengukuran prioritas kepentingan dari kriteria-kriteria dalam pemilihan supplier diperoleh melalui kuesioner yang dibagikan kepada responden yang berjumlah 6 orang yaitu direktur teknik, manajer representatif, kepala bagian pembelian, satu karyawan IT, dan dua orang karyawan bagian pembelian dan pergudangan yang bertugas menerima barang.

Tabel 8 Penilaian Prioritas Kepentingan Kriteria Dalam Pemilihan Supplier

\begin{tabular}{|c|l|l|l|l|l|}
\hline $\begin{array}{c}\text { Kriteri } \\
\mathbf{a}\end{array}$ & $\begin{array}{c}\text { Har } \\
\text { ga }\end{array}$ & $\begin{array}{c}\text { Kuali } \\
\text { tas }\end{array}$ & $\begin{array}{c}\text { Laya } \\
\text { nan }\end{array}$ & $\begin{array}{c}\text { Ketepat } \\
\text { an } \\
\text { Pengiri } \\
\text { man }\end{array}$ & $\begin{array}{c}\text { Ketepa } \\
\text { tan } \\
\text { Jumla } \\
\mathbf{h}\end{array}$ \\
\hline Harga & 1 & 0,088 & 0,214 & 0,121 & 0,120 \\
\hline $\begin{array}{c}\text { Kualita } \\
\text { s }\end{array}$ & $\begin{array}{l}0,24 \\
0\end{array}$ & 1 & 0,357 & 0,152 & 0,149 \\
\hline $\begin{array}{c}\text { Layana } \\
\text { n }\end{array}$ & $\begin{array}{l}0,04 \\
0\end{array}$ & 0,035 & 1 & 0,121 & 0,122 \\
\hline $\begin{array}{c}\text { Ketepat } \\
\text { an } \\
\text { Pengiri } \\
\text { man }\end{array}$ & 0,60 & 0,702 & 0,357 & 1 & 0,400 \\
\hline $\begin{array}{c}\text { Ketepat } \\
\text { an }\end{array}$ & 0,12 & 0,149 & 0,122 & 0,400 & 1 \\
Jumlah & 0 & & & & \\
\hline
\end{tabular}

Sumber : (Henny Hartono, Johanes Fernandes Andry \& Gunawan, 2019)
Setelah penilaian dari 6 responden didapatkan, kemudian hasilnya dirata-rata menggunakan rata-rata geometric (geometric mean) dengan rumus. Hal ini dilakukan karena AHP hanya memerlukan satu jawaban untuk matriks perbandingan. Hasilnya ditunjukkan pada tabel 8 .

Dari hasil perhitungan perbandingan berpasangan antar variabel dalam memilih supplier di atas diperoleh bobot yang ditunjukkan dalam tabel 9.

Tabel 9. Prioritas Kepentingan (Bobot) Kriteria dalam Pemilihan Supplier

\begin{tabular}{|c|c|c|}
\hline Kriteria & Bobot & Prioritas \\
\hline Harga & 0,136 & IV \\
\hline Kualitas & 0,231 & III \\
\hline Layanan & 0,067 & V \\
\hline $\begin{array}{c}\text { Ketepatan } \\
\text { Pengiriman }\end{array}$ & 0,566 & I=II \\
\hline Ketepatan Jumlah & 0,566 & I=II \\
\hline
\end{tabular}

Sumber : (Henny Hartono, Johanes Fernandes Andry \& Gunawan, 2019)

Tabel 9 menunjukkan bahwa dalam memilih supplier barang elektronik, prioritas pertama dari suatu perusahaan manufaktur yaitu kriteria ketepatan pengiriman dan jumlah barang dengan bobot 0,566 , selanjutnya prioritas ketiga yaitu kriteria kualitas dengan bobot 0,231, prioritas keempat kriteria harga dengan bobot 0,136 , prioritas selanjutnya layanan dengan bobot yaitu 0,067 .

\section{Memilih Supplier Optimal}

Tabel 10 Bobot Alternatif Secara Keseluruhan

\begin{tabular}{|l|l|c|}
\hline \multicolumn{1}{|c|}{ Alternatif } & Bobot & Prioritas \\
\hline Supplier $\mathrm{W}$ & 0,185 & III \\
\hline Supplier X & 0,276 & II \\
\hline Supplier Y & 0,183 & IV \\
\hline Supplier Z & 0,356 & I \\
\hline
\end{tabular}

Sumber : (Henny Hartono, Johanes Fernandes Andry \& Gunawan, 2019)

Setelah masing-masing kriteria dan alternatif didapatkan kemudian dilakukan sintesis untuk mendapatkan bobot alternatif secara keseluruhan dari kriteria yang ada, bobot masingmasing alternatif secara keseluruhan dapat dihitung dengan menjumlahkan semua bobot keseluruhan pada masing-masing supplier, hasilnya ditunjukkan pada tabel 10 .

Tabel 10 menunjukkan bahwa secara keseluruhan, supplier $\mathrm{Z}$ dengan nilai bobot 0,356 merupakan prioritas pertama untuk dipilih sebagai supplier barang elektronik pada suatu perusahaan manufaktur.

Prioritas kedua adalah supplier $\mathrm{X}$ dengan nilai bobot 0,276 . Prioritas ketiga adalah supplier $\mathrm{W}$ dengan nilai bobot 0,185 , sedangkan prioritas 
terakhir adalah supplier $\mathrm{Y}$ dengan nilai bobot 0,183 . Pemilihan supplier jika didasarkan pada masing-masing kriteria dapat dilihat pada tabel 11 berikut ini:

Tabel 11. Bobot Alternatif (Supplier) Berkenaan dengan Kriteria

\begin{tabular}{|l|l|l|l|l|}
\hline Kriteria & $\begin{array}{l}\text { Supplier } \\
\text { W }\end{array}$ & $\begin{array}{l}\text { Supplier } \\
\text { X }\end{array}$ & $\begin{array}{l}\text { Supplier } \\
\text { Y }\end{array}$ & Supplier Z \\
\hline Harga & 0,174 & 0,293 & 0,044 & 0,489 \\
\hline Kualitas & 0,511 & 0,035 & 0,173 & 0,280 \\
\hline Layanan & 0,212 & 0,048 & 0,422 & 0,319 \\
\hline $\begin{array}{l}\text { Ketepatan } \\
\text { pengiriman }\end{array}$ & 0,051 & 0,397 & 0,192 & 0,360 \\
\hline
\end{tabular}

Sumber : (Henny Hartono, Johanes Fernandes Andry \& Gunawan, 2019)

Tabel 11 menunjukkan bahwa masingmasing supplier memiliki keunggulan masingmasing dalam memenuhi kriteria yang ada. Seperti supplier $\mathrm{W}$ yang memiliki unggul dalam kriteria kualitas barang, supplier $\mathrm{X}$ unggul dalam kriteria ketepatan pengiriman, supplier Y unggul dalam kriteria layanan, dan supplier $\mathrm{Z}$ unggul dalam kriteria harga.

\section{Indeks Konsistensi}

Penggunaan metode AHP bisa saja dilakukan dengan mengisi nilai prioritas yang tidak konsisten. Memakai persepsi manusia dalam menginputnya maka ketidakkonsistenan mungkin terjadi karena manusia memiliki keterbatasan dalam menyatakan persepsinya secara konsisten terutama kalau harus membandingkan banyak kriteria. Jika hal ini terjadi, maka solusi yang dihasilkan dari metode AHP bukan yang terbaik.

Pengukuran konsistensi ini dimaksudkan untuk melihat ketidakkonsistenan respon yang diberikan responden. Jika $\mathrm{CR}<0,1$ maka nilai perbandingan berpasangan pada matriks kriteria yang diberikan konsisten. Jika CR > 0,1 maka nilai perbandingan berpasangan pada matriks kriteria yang diberikan tidak konsisten. Sehingga jika tidak konsisten, maka pengisian nilai-nilai pada matriks berpasangan pada unsur kriteria maupun alternatif harus diulang.

Langkah-langkah pengecekkan konsistensi hasil metode AHP dan penerapannya:

1) Hitung perkalian antara matriks awal dengan matriks nilai eigen yang terakhir

$$
\mathrm{A} * \mathrm{~W}^{\mathrm{T}}
$$

A: matriks awal

$\mathrm{W}^{\mathrm{T}}$ : matriks nilai eigen dalam format baris

2) Hitung (t):

$$
\frac{1}{\mathrm{n}} \sum_{\mathrm{i}=1}^{\mathrm{i}=\mathrm{n}} \frac{i \text { th entry in } \mathrm{AW}^{\mathrm{T}}}{i \text { th entry in } \mathrm{W}^{\mathrm{T}}}
$$

3) Hitung CL:

$$
\begin{gathered}
\mathrm{Cl}=\frac{\text { Hasil Langkah 2-n }}{\mathrm{n}-1} \\
\mathrm{n} \text { : jumlah objek }
\end{gathered}
$$

4) Hitung CR

$$
\mathrm{CR}=\frac{\mathrm{Cl}}{\mathrm{RI}}
$$

Jika Un V= v, $0(10 \%)$ maka derajat kekonsistenan memuaskan. Jika CR > 0,10 maka ada ketidakkonsistenan saat menerapkan skala perbandingan sepasang kriteria. Jika masalah ini terjadi, berarti solusi metode AHP tidik berarti bagi pengguna.

Hasil CR menyimpulkan bahwa proses perbandingan antara dua kriteria dilakukan secara konsisten. Secara umum dapat dilihat bahwa:

1. Harga memang sangat dipertimbangkan, tetapi kualitas setingkat lebih tinggi dan layak untuk dipertimbangkan, dan harga cukup diutamakan dari layanan.

2. Kualitas diutamakan daripada layanan.

3. Ketepatan pengiriman sangat berpengaruh terhadap kondisi dan kualitas suatu barang.

4. Pengisian ini memperlihatkan konsistensi pengguna, sehingga metode AHP menyimpulkan bahwa prioritas tertinggi adalah ketepatan pengiriman, disusul dengan kualitas, harga, dan layanan.

\section{KESIMPULAN}

Berdasarkan tujuan penelitian dan hasil penelitian di atas maka dapat disimpulkan beberapa hal berikut ini:

Ketetapan kriteria dan konsistensi dalam pemilihan supplier sangat penting dalam pengambilan keputusan. Perlu dilakukannya seleksi yang ketat dan perhitungan yang sangat matang dalam menentukan dan mengetahui urutan yang tepat dalam menentukan prioritas kriteria dan subkriteria pemilihan pemasok barang pada perusahaan.

Jumlah kandidat dan jumlah faktor/kriteria dalam metode AHP akan mempengaruhi konsistensi pengguna saat memberikan penilaian perbandingan. Consistency Index dihitung untuk memastikan tingkat konsistensi pengambilan keputusan saat mengisi nilai perbandingan antar sepasang objek. 


\section{DAFTAR PUSTAKA}

Ahmad Fauzi. (2016). Decision Support System Dalam Menentukan Pemasok Infrastruktur IT. Studi Kasus: PT Cipta Karya Komputer. Jurnal Bina Sarana Informatika, 4 No 2.

Basuki, A. (2010). Perancangan Sistem Pendukung Keputusan Pemilihan Pemasok Dengan Pendekatan Fuzzy Analytical Hierarchy Process (Fuzzy Ahp). Rekayasa, 3(1), 42-50. https://doi.org/http://doi.org/10.21107/rekay asa.v3i1.2289

Dewayana, T., \& Budi, A. (2009). Pemilihan Pemasok Cooper ROD Menggunakan Metode ANP (Studi Kasus: PT. Olex Cables Indonesia (OLEXINDO)). J@Ti Undip, IV(3), 212-217.

Henny Hartono, Johanes Fernandes Andry, B.G. L. I., \& Gunawan, C. (2019). Decision Support System Perusahaan Manufacturing Dalam Menentukan Pemasok Menggunakan Metode Analytical Hierarchy Process.
Munthafa, A., \& Mubarok, H. (2017). Penerapan Metode Analytical Hierarchy Process Dalam Sistem Pendukung Keputusan Penentuan Mahasiswa Berprestasi. Jurnal Siliwangi, 3(2), 192-201.

Nurmalasari \& Pratama, A. A. (2018). Sistem Pendukung Keputusan Pemilihan Supplier Menggunakan Metode AHP Pada PT Transcoal Pacific Jakarta. Jurnal Teknik Komputer, IV no 2.

Reny Rahmayanti. (2010). Analisis Pemilihan Pemasok Menggunakan Metode Analytical Hierarchy Process (AHP). Studi Kasus Pada PT Cazikhal. Universitas Sebelas Maret Surakarta.

Sasongko, A, Astuti, I. F., \& Maharani, S. (2017). Pemilihan Karyawan Baru Dengan Metode AHP (Analytic Hierarchy Process). Informatika Mulawarman: Jurnal Ilmiah Ilmu Komputer, 12 (2), 88. https://doi.org /10.30872/jim.v12i2.650 